\title{
A DISCUSSÃO EM TORNO DA REDUÇÃO DA MAIORIDADE PENAL: UM DEBATE ENTRE POLÍTICAS PÚBLICAS, SIMBOLISMOS E NEUROCIÊNCIA
}

\section{THE DISCUSSION AROUND THE REDUCTION OF CRIMINAL MAJORITY: A DEBATE BETWEEN PUBLIC POLICY, SYMBOLISM AND NEUROSCIENCE}

\author{
Carlos Eduardo Adriano Japiassú ${ }^{1}$ \\ Rodrigo de Souza Costa²
}

\section{Resumo}

A temática da redução da maioridade penal costuma surgir em face de uma intensa discussão realizada em torno da criminalidade urbana que finda por estar presente no dia a dia das grandes cidades. Apesar de não haver uma exposição clara entre a vinculação desse tipo de medida com o tipo de criminalidade presente no cotidiano das grandes cidades, o Brasil se vê inserido num debate sobre o tema em virtude da apreciação por parte do Congresso Nacional da Proposta de Emenda Constitucional n.o 171 que propõe essa redução para o patamar de 16 anos. Fato é que as discussões em torno dessa realidade jurídica poucas vezes leva em conta os fundamentos da escolha política do patamar de maioridade penal. Assim, pretende-se no artigo entender qual a fundamentação em torno do patamar de maioridade penal, sob esse prisma, sua vinculação como medida de política criminal destinada ao controle da violência urbana.

Palavras-chaves: Direito Penal; Maioridade penal; violência urbana;

\section{Abstract}

The theme of reduction of the minimum age for criminal responsibility often arises in the context of the intense discussion held around urban crime, a reality that afflicts the cities. Although there is no clear link between this topic and the type of crime present in daily life in large cities, Brazil has been inserted into a debate on the issue because of the assessment by the Brazilian Parliament of National Constitutional Amendment Proposal No. 171 which proposes the reduction of the minimum age to criminal liability to the age of 16 years. The debates around this legal reality rarely takes into account the fundamentals of political choice of the minimum age to criminal liability. So, it is intended in this paper to understand what reasons are surrounding this legal choice and its possible link to criminal policy measure intended to control urban violence.

\footnotetext{
${ }^{1}$ Professor Associado de Direito Penal da UERJ e da UFRJ, Coordenador do Programa de Pós-Graduação em Direito da UNESA, Secretário-Geral da Associação Internacional de Direito Penal (AIDP) e Presidente Honorário do Grupo Brasileiro da AIDP. E-mail: japiassu@uerj.br

2 Professor Adjunto de Direito Penal da UERJ e Secretário-Geral Adjunto do Grupo Brasileiro da Associação Internacional de Direito Penal (AIDP). E-mail: rodrigo.costa@uerj.br
} 
Keywords: Criminal law; Criminal liability, urban violence, violent criminality INTRODUÇÃO

A temática da segurança, sempre presente no cotidiano das grandes cidades brasileiras, serve como principal fonte de pesquisa e, simultaneamente, pano de fundo para o trabalho que ora se apresenta.

Isso pode ser percebido a partir da verificação que as políticas de segurança têm influência primordial no dia-a-dia das grandes cidades. A circulação das pessoas, os empreendimentos imobiliários que são construídos, o preço dos imóveis e dos serviços disponíveis são, de alguma maneira, influenciados pela sensação de segurança possuída em determinada localidade, bem como pela atuação dos órgãos públicos pretensamente garantidores dessa mesma sensação ${ }^{3}$.

O processo político-eleitoral, em pauta no Brasil a cada dois anos, mostra a centralidade que a noção de segurança vem adquirindo com o passar do tempo, tornando-se, cada vez mais, tema central e decisivo das campanhas.

A mídia organizada criou quase que um subgrupo que lida exclusivamente com as questões que, pelo menos em tese, são tratadas como afeitas aos dispositivos de segurança, gerando-se uma indústria da informação especializada nesse campo de atuação.

É bastante comum ver-se a temática da segurança exclusivamente ligada ao fenômeno criminal. Apesar disso não ser obrigatório, são as manifestações típicas do fenômeno da violência e aquelas que se ligam a algumas formas de criminalidade que fazem surgir o debate acalorado em torno da noção de segurança e das políticas que dela são oriundas.

Talvez não seja exagero afirmar que, em linhas gerais, a política criminal é, na verdade, a política de segurança, uma vez que, invariavelmente, o Direito Penal é chamado a socorrer os problemas constatados por essas políticas.

Uma das questões que mais aflige e preocupa as cidades brasileiras e o país como um todo é a criminalidade, particularmente a chamada criminalidade violenta.

Pode-se dizer, portanto, que a sociedade brasileira é traumatizada por essa violência e, por esse motivo, existe um forte clamor popular por medidas que lidem com esse problema. Para lidar

\footnotetext{
${ }^{3}$ Sobre o tema ver COSTA, Rodrigo de Souza. Direito Penal e Segurança. Rio de Janeiro: GZ Editora, 2012.
} 
como isso, não raro, com apoio popular expressivo, têm sido aprovadas normas penais, pretendendo os legisladores que sejam respostas quase sempre mais duras aos crimes.

A lei penal ${ }^{4}$ e a Constituição brasileira ${ }^{5}$ fixam a idade da maioridade penal aos 18 anos. Todavia, com frequência, a prática de fatos definidos como crime por adolescentes tem gerado, no Brasil, recorrentes debates sobre sua redução para 16 anos.

Nesse contexto, está em tramitação o Projeto de Emenda Constitucional no 171/1993, que pretende modificar o art. 228, da Constituição Federal, que se refere à maioridade penal. Este Projeto tem sido aprovado em diversas instâncias no Parlamento brasileiro e tem sido debatido intensa e apaixonadamente no Brasil, com posições radicais quanto à adequação ou não da medida.

No presente texto, pretende-se apresentar a discussão e os seus fundamentos. Para tanto, inicialmente, debater-se-á a legislação brasileira em torno do tema para, em seguida, discutir-se o significado em torno da noção de responsabilidade penal e a inserção da temática da maioridade penal dentro da Teoria do Crime do Direito Penal. A seguir, será verificada a contribuição que a neurociência tem dado para a matéria, em face do principal argumento elencado em favor da redução, para concluir-se o texto tentando-se compreender se tal debate é realizado como forma de discutir-se uma política pública de enfrentamento da violência urbana ou algo meramente simbólico sem a segurança de reflexos efetivos no dia a dia das grandes cidades.

\section{LEGISLAÇÃO BRASILEIRA}

A distinção de punição entre adultos e adolescentes é antiga. Ao longo da história, as legislações têm oscilado entre tendências diferenciadoras e não diferenciadoras da responsabilidade pela prática de fatos definidos como criminosos por adolescentes e por adultos. ${ }^{6}$

Inicialmente, não se fazia distinção entre maiores e menores. Foi assim, por exemplo, no Código de Hammurabi e no direito grego. Modificação surgiu no Direito Romano. Na Lei das XII Tábuas (449 a.C.), surgiu a distinção entre púberes e impúberes, que tinham a pena atenuada por não terem o estado intelectual de discernimento completo. ${ }^{7}$

\footnotetext{
${ }^{4}$ Artigo 27 do Código Penal.

${ }^{5}$ Artigo 228 da Constituição Federal.

${ }^{6}$ SHECAIRA, Sérgio Salomão. Sistemas de garantias e o direito penal juvenil. São Paulo: RT, 2008, p. 21

${ }^{7}$ Idem, p. 22-24.
} 
Com o Código de Justiniano, foi incluído que, até a puberdade - 14 anos para varões e 12 para viragos -, para que houvesse punição, era necessário que se demonstrasse o discernimento e, portanto, a ausência de malícia. ${ }^{8}$

O critério do discernimento foi utilizado a partir daí e ao longo das eras seguintes. Só muito posteriormente o critério de idade fixa, como adotado hoje pela legislação brasileira, surgiu para o reconhecimento da responsabilidade penal de adolescentes e, por conta disso, passar-se-á à apresentação do histórico no Brasil.

Na legislação brasileira, o Código Criminal de 1830 estabelecia, em seu artigo 10, §1ํ., que o menor de 14 anos não seria penalmente responsável. ${ }^{9} \mathrm{~A}$ exceção a esta regra constava do artigo 13 do mesmo diploma legislativo, que afirmava que o menor de 14 anos, caso tivesse agido com discernimento, deveria ser recolhido às casas de correção pelo tempo que o juiz considerasse necessário, desde que não ultrapassasse a idade de 17 anos. ${ }^{10}$

O primeiro Código Penal republicano, de 1890, não representou grande modificação quanto à adoção do critério do discernimento, já que estabelecia não serem responsáveis os menores de 9 anos e, de 9 a 14 anos, deveria ser verificado o discernimento. ${ }^{11}$

Tanto a legislação imperial quanto a republicana pertencem a um período que se convencionou chamar de etapa penal indiferenciada, em que a legislação tratava de maneira quase idêntica adolescentes e maiores, inclusive quanto aos estabelecimentos penais que cumpririam suas

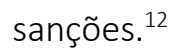

Tal entendimento somente se modificou, em países ocidentais, no final do século XIX, como consequência de inovações de natureza criminológica e político criminal, que pretendiam impedir que

\footnotetext{
8 Idem, p. 24.

${ }^{9}$ Código Criminal do Império do Brasil: "Art. 10. Também não se julgarão criminosos: $\S 1$ o - Os menores de quatorze annos."

${ }^{10}$ Código Criminal do Império do Brasil: "Art. 13. Se se provar que os menores de quatorze anos, que tiverem cometido crimes, obrárão com discernimento, deveráõ ser recolhidos ás casas de correcção, pelo tempo que ao juiz parecer, comtanto que o recolhimento não exceda a idade de dezessete annos".

${ }^{11}$ Código Penal de 1890: "Art. 27. Não são criminosos:

$\S 1$. Os menores de 9 annos completos;

$\S 2$ ․ Os maiores de nove e menores de 14, que obrarem sem discernimento".

12 Shecaira, op. cit., p. 28.
} 
o adolescente pudesse se tornar delinquente. Como consequência, o tratamento dispensado para a criminalidade juvenil passou a ser educativo e reformador. ${ }^{13}$

No Brasil, tal modificação se deu a partir do orçamento de 1921 (Lei no. 4.242/1921), que, em seu artigo 3ํ., §20, estabeleceu que o menor de 14 anos, autor ou cúmplice de crime, não seria submetido a processo algum, e o menor de 14 a 18 anos, seria submetido a processo especial. Tal dispositivo, de maneira expressa, revogou o Código de 1890 quanto a este tema. ${ }^{14}$

Assim, foi inaugurada, na legislação brasileira, a chamada etapa tutelar, que se consolidou com o surgimento do Código de Menores, chamado de Código Mello Mattos (Decreto Federal n ‥ 17.943/1927), que estabeleceu a doutrina da situação irregular, ao se referir ao menor abandonado ou delinquente e determinando que o menor de 18 anos seria submetido a medidas de assistência e proteção. $^{15}$

Já a Consolidação das Leis Penais (1932), ${ }^{16}$ fixou, em seu artigo $27^{17}$, que não seriam considerados criminosos os menores de 14 anos e, no artigo 30, ${ }^{18}$ que os menores de 18 anos abandonados e delinquentes seriam submetidos ao regime do Código de Menores.

A idade de 18 anos também foi mantida no Código Penal de 1940, fazendo com que fossem os adolescentes considerados como penalmente irresponsáveis e submetidos à legislação específica para eles. ${ }^{19}$ A disposição sintética do Código Penal foi fundamentada também de maneira breve em sua

\footnotetext{
${ }^{13}$ BRUNO, Aníbal. Direito penal, parte geral, tomo 2o: fato punível. Rio de Janeiro: Forense, 2005, p. 108, nota 11. ${ }^{14}$ MASSA, Patricia Helena. A menoridade penal no direito brasileiro. Revista Brasileira de Ciências Criminais, n. 4, São Paulo: RT, out.-dez. 1993, p. 128.

${ }^{15}$ A doutrina da situação irregular é criticada por não distinguir o menor que necessita de proteção (abandonado) do que necessita de reforma (delinquente), reunindo ambos em um mesmo estabelecimento (SHECAIRA, op. cit., p. 36).

16 “(...) para remediar as dificuldades oriundas da legislação penal, que fora tremendamente modificada ao longo da assim chamada República Velha, o desembargador Vicente Piragibe criou uma consolidação das leis penais vigentes. Seu trabalho tornou-se lei pelo Decreto no 22.213, de 14 de dezembro de 1932, que fez com que a Consolidação das Leis Penais se tornasse o novo estatuto penal brasileiro". (SOUZA, Artur de Brito Gueiros; JAPIASSÚ, Carlos Eduardo Adriano. Curso de direito penal: parte geral. Rio de Janeiro: Elsevier, 2012, p.53).

${ }^{17}$ Consolidação das Leis Penais: "Art. 27. Não são criminosos: $\S 1$ o. os menores de 14 annos;"

18 Consolidação das Leis Penais: "Art. 30. Os menores de 18 annos, abandonados e delinquentes, ficam submetidos ao regimen estabelecido pelo decreto n. 17.943-A, de 12 de Outubro de 1927, Código de Menores".

${ }^{19}$ Código Penal de 1940: "Art. 23. Os menores de dezoito anos, são penalmente irresponsáveis, ficando sujeitos às normas estabelecidas na legislação especial”.
} 
Exposição de Motivos, que justificou não tratar dos imaturos (menores de 18 anos) e deixá-los inteira e irrestritamente fora do Direito Penal, sujeitos apenas "à pedagogia corretiva de legislação especial". ${ }^{20}$

Diferentemente da legislação anterior o Código Penal de $1969,{ }^{21}$ que não chegou a viger no Brasil, manteve a idade de 18 anos, mas estabeleceu que o menor entre 16 e 18 anos, , $^{22}$ se revelasse desenvolvimento psíquico para entender o caráter ilícito do fato e de determinar-se segundo esse entendimento. Significa dizer que "o legislador tentou ressuscitar o discernimento". ${ }^{23}$

Ou seja, foi somente na primeira metade do século XX que a legislação brasileira incorporou o critério da idade e, pouco mais de 30 anos após, houve essa tentativa de retorno ao modelo anterior. Sustentou-se tal opção no fato de que as legislações penais no mundo adotarem a idade de 16 anos e que parecia aos autores do Código que tal medida aumentaria a consciência da responsabilidade social dos jovens. ${ }^{24}$

Em 1979, surgiu o novo Código de Menores (Lei №. 6.697/1979), que, em grande medida, manteve o que vigera com o Código Mello Mattos: a ideia de situação irregular do menor e a equiparação do menor carente com o infrator. ${ }^{25}$ Quanto à idade penal, manteve-a aos 18 anos.

20 PIERANGELLI, José Henrique. Códigos penais do Brasil: evolução histórica. Bauru: Jalovi, 1980, p.422.

21 "Em 1961, o Governo brasileiro decidiu promover uma reforma do Código Penal brasileiro. Foi confiada a Nelson Hungria a tarefa de elaborar um anteprojeto, que veio, afinal, a ser apresentado em 1963, dando-se-Ihe ampla divulgação.

Em 1964, o Ministro da Justiça, Milton Campos, designou comissão revisora, da qual fizeram parte não só o autor, mas também os professores Aníbal Bruno e Heleno Cláudio Fragoso. O trabalho desta comissão não chegou a ser divulgado.

O anteprojeto foi, então, submetido a nova comissão, desta feita composta por Benjamin Moraes Filho, Heleno Cláudio Fragoso e Ivo D’Aquino, dada a necessidade de uniformizar os textos dos projetos de Código Penal e de Código Penal Militar.

O projeto foi promulgado pelo Decreto-Lei no 1.004, de 21 de outubro de 1969, para que entrasse em vigor em 1 o de agosto de 1970. O prazo de vacância foi, entretanto, sucessivamente prorrogado, sob o argumento que dever-se-ia aguardar a aprovação do novo Código de Processo Penal, de autoria do Professor José Frederico Marques. Afirmava-se pretender que ambos os Estatutos Penais entrassem em vigor juntos.

Já em 31 de dezembro de 1973, pela lei no 6.016, em atendimento às inúmeras críticas que foram formuladas ao Código, foram feitas mudanças no modelo original.

Após quase dez anos de vacância, em 11 de novembro de 1978, a lei no 6.578 finalmente revogou o Código Penal de 1969, por já não mais corresponder às necessidades do país" (SOUZA, JAPIASSÚ, op. cit., p. 55).

${ }^{22}$ Código Penal de 1969: "Art. 33 - O menor de dezoito anos é inimputável.

Art. 34 - Os menores de dezoito anos ficam sujeitos às medidas educativas, curativas ou disciplinares determinadas em leis especiais".

${ }^{23}$ MASSA, op. cit., p. 129.

24 PIERANGELLI, op. cit., p. 584.

25 SHECAIRA, op. cit, p. 42. 
Com a Parte Geral de 1984, reproduziu-se o que dispusera o Código Penal de 1940. Isto é, o seu art. 27 estabelece que os menores de 18 anos são penalmente inimputáveis, sujeitando-se, pelos fatos antijurídicos praticados, ao disposto na legislação especial. ${ }^{26}$

Note-se que, apenas quatro anos após a promulgação da Parte Geral do Código Penal, a Constituição Federal de 1988 estabeleceu o Título VIII (Da Ordem Social), em que havia capítulo específico sobre a Família, Criança, Adolescente e Idoso (arts. 227 a 229). Nesse capítulo, o legislador constitucional reproduziu essa norma, de forma idêntica àquela consagrada no Código Penal, conforme os termos do art. 228. ${ }^{27}$

Como consequência, surgiu legislação específica, o chamado Estatuto da Criança e da Adolescente (Lei no 8.069/1990), que inaugura a chamada etapa garantista, em que houve a substituição do paradigma da situação irregular pelo da proteção integral. Ao lado disso, foi estabelecida justiça especializada.

Assim, os adolescentes (entre 12 e 18 anos) que praticarem fatos definidos como crime serão submetidas a medidas socioeducativas (advertência, obrigação de reparar dano, prestação de serviços à comunidade, liberdade assistida, inserção em regime de semiliberdade ou internação estabelecimento educacional).

Em que pese, portanto, na legislação vigente, a imputabilidade se iniciar aos 18 anos, ficou estabelecido um sistema de medidas para os adolescentes.

\section{MAIORIDADE PENAL}

\section{A necessária precisão no uso do termo responsabilidade penal}

Inicialmente deve-se estabelecer uma discussão prévia que, apesar de óbvia, pode esconder uma distinção doutrinária importante: o significado do termo responsabilidade penal.

Isto acontece porque, no Brasil, sem maiores divergências, quando o termo responsabilidade penal é utilizado, este se refere à possibilidade de sancionar-se um maior de dezoito anos com uma das três espécies de pena previstas no artigo 32 do Código Penal brasileiro: privação da liberdade,

${ }^{26}$ Código Penal, com redação da Lei no. 7.209/1984: “Art. 27 - Os menores de 18 (dezoito) anos são inimputáveis, ficando sujeitos às normas estabelecidas na legislação especial".

${ }^{27}$ Constituição Federal de 1988: "Art. 228. São penalmente inimputáveis os menores de dezoito anos, sujeitos às normas da legislação especial”. 
restrição de direitos ou multa. A responsabilização jurídica do menor de dezoito anos, possível na legislação nacional a partir dos doze $\operatorname{anos}^{28}$, ocorre nas Varas da Infância de Juventude com a submissão do adolescente a uma medida socioeducativa ${ }^{29}$.

Entretanto, não é incomum ver-se a menção, principalmente na doutrina europeia seja a uma responsabilidade penal de menores ${ }^{30}$ seja a um sistema penal especial para menores ${ }^{31}$, sendo certo que esses são sinônimos da responsabilização socioeducativa de adolescentes.

Não há distinção substancial entre as medidas preconizadas pelos ordenamentos jurídicos estrangeiros que qualificam tais sanções como de natureza penal e aquelas previstas no ordenamento jurídico brasileiro como socioeducativas, portanto de natureza extrapenal ${ }^{32}$.

Desta forma, percebe-se que um primeiro cuidado deve ser tomado. Se considerado o critério acima enunciado, que utiliza o conceito de responsabilização penal de menores, chega-se à conclusão de que, apesar da maioridade penal no Brasil ser consagrada aos dezoito anos, a responsabilização penal pode ocorrer a partir dos doze anos, idade a partir da qual o adolescente pode sofrer sanção jurídica pelos seus atos praticados.

Isto posto, torna-se necessário esclarecer a inserção da noção de maioridade penal dentro da Teoria do Crime, especialmente nas noções de culpabilidade e de imputabilidade.

\section{Maioridade penal e Teoria do Crime}

Em direito penal, o tema da maioridade e da menoridade se insere, na estrutura do crime, na culpabilidade.

A culpabilidade tem como pressuposto lógico a liberdade de decisão ou de escolha da pessoa humana, ou, em outras palavras, a capacidade antropológica de se determinar no sentido da norma jurídica. A responsabilidade penal somente pode incidir sobre aquele que possuía aptidão de dominar seus instintos ao invés de cometer o fato antijurídico. Conforme explicitado por Jescheck e Weigend,

\footnotetext{
${ }^{28}$ Artigo 105 da Lei n. 8.069/90.

${ }^{29}$ Artigo 112 da Lei n.o 8.069/90.

30 OTTENHOF, Reynald. La résponsabilité pénale des mineurs dasn l'ordre interne et internacional. In Revue Internationale de Droit Pénal. 2004/1. Vol. 75. Toulouse, Érès, p. 25-50.

${ }^{31}$ Resolutions of the XVII International Congress of Penal Law. In Nouvelles ètudes Pénales. N.21, Toulouse: Érès, 2009, disponível em http://www.penal.org/sites/default/files/NEP21anglais.pdf

32 OTTENHOF, op. cit. p. 25-50.
} 
no terreno da culpabilidade, faz-se necessário apartar os processos causais naturais da força da vontade humana. ${ }^{33}$

Vê-se, portanto, que a culpabilidade exige o enfrentamento da problemática do livre-arbítrio. A compreensão da censura de natureza jurídico-penal não requereria, dessa forma, um maior aprofundamento, sendo suficiente a noção de que a responsabilidade de uma pessoa adulta, mentalmente inserida num patamar médio de sanidade, se constitui numa realidade incontestável da consciência social e moral. Atua-se em sociedade a partir da certeza da liberdade como pressuposto da sua conduta, esperando, da mesma maneira, que o outro comporte-se igualmente livre. ${ }^{34}$

Pode-se dizer que a responsabilização penal passa a consistir na reprovabilidade da conduta ilícita (típica e antijurídica) de quem tem capacidade genérica de entender e querer (imputabilidade) e podia, nas circunstâncias em que o fato ocorreu conhecer a sua ilicitude, sendo-lhe exigível comportamento que se ajuste ao direito.

Assim, são três os elementos ou requisitos da culpabilidade: 1이마. conhecimento da ilicitude; e 3을 Exigibilidade de conduta diversa.

Neste contexto, imputabilidade é a capacidade de livre autodeterminação. Ou, dito de outra forma, é o conjunto de condições pessoais que dão ao agente a faculdade de atuar de modo distinto, permitindo, assim, que lhe seja atribuída juridicamente a responsabilidade pelo injusto típico. Ausente a imputabilidade, não haverá que falar em liberdade de autodeterminação, sendo, portanto, desculpável pelo fato que praticou.

Aquele que, por não possuir maturidade penalmente suficiente ou por sofrer de graves alterações psíquicas, não detiver a capacidade de compreensão ou de autodeterminação conforme o Direito, não poderá receber a nota de reprovabilidade. Dessa forma, há dois requisitos necessários para que se estabeleça a imputabilidade de um indivíduo: maturidade e sanidade.

Para o presente texto, interessa discutir somente a maturidade.

Observe-se, no particular, que o legislador não informa o que vem a ser imputabilidade, mas, ao inverso, apresenta, nos arts. 26 , caput, 27 , e $28, \S 1^{\circ}$, do CP, hipóteses legais de inimputabilidade.

\footnotetext{
33 JESCHECK, Hans-Heinrich; WEIGEND, Thomas. Tratado de Derecho Penal. Parte General. 5a ed. Trad. Olmedo Cardenete. Granada: Comares, 2002, p. 438.

${ }^{34}$ Idem, p. 441.
} 
Assim, se imputabilidade é a capacidade de responsabilização de alguém por seus atos antijurídicos, ao revés, inimputabilidade é a ausência de tal capacidade.

Com base nos avanços científicos então verificados, o Código Penal de 1940 procurou regular a questão da inimputabilidade de forma mais técnica possível. Assim, na Exposição de Motivos, estabeleceu-se que, na fixação do pressuposto da responsabilidade penal, baseada na capacidade de culpa moral, apresentam-se três sistemas: o biológico ou etiológico, o psicológico e o biopsicológico.

A propósito, esclarece-se que o sistema biológico é aquele que condiciona a responsabilidade à saúde mental, isto é, à normalidade da mente. Se o agente é portador de uma enfermidade ou grave deficiência mental, deve ser declarado irresponsável, sem a necessidade de ulterior indagação sobre sua aptidão de compreensão do caráter antijurídico do fato no momento da sua prática.

Por sua vez, o método psicológico despreza, a princípio, fatores patológicos, fiando-se na constatação da irresponsabilidade penal se, no momento da ação, não dispunha, o agente, da capacidade cognitiva da natureza do fato (aspecto intelectivo) ou, ainda, se não dispusesse de condições de se determinar de acordo com essa apreciação (aspecto).

Por fim, o método biopsicológico busca uma solução de consenso, ou seja, considera excluída a imputabilidade penal por intermédio da conjugação dos sistemas anteriores. A responsabilidade somente é afastada se: 1으 o agente sofrer de enfermidade ou retardo mental; e 2o se no momento da conduta era incapaz de entendimento ou de controle dos seus impulsos antijurídicos.

Este último sistema foi adotado pelo legislador penal, para os casos de doença mental e de desenvolvimento mental incompleto ou retardado, conforme a redação do art. 26, caput, e seu parágrafo único, do CP. Apenas no tocante à menoridade penal é que se adotou o sistema biológico.

Isto, pois, como já mencionado, dispõe o art. 27, do Código Penal e o art. 228 da Constituição Federal, os menores de 18 anos são penalmente inimputáveis, sujeitando-se, pelos fatos antijurídicos praticados, ao disposto na legislação especial.

Dessa maneira, aquele que ainda não completou aquela idade, não tem, segundo presunção absoluta do ordenamento jurídico, o grau de maturidade para fazer-se penalmente responsável. Pressupõe-se, por critérios político-criminais, seu desenvolvimento mental incompleto. No dia que completa essa idade - na data do seu aniversário de 18 anos -, cessa a inimputabilidade, passando o mesmo a ser considerado plenamente imputável, salvo, é claro, se for portador de enfermidade 
mental. Na hipótese de não existência de documentação comprobatória da verdadeira idade de determinado indivíduo, deve o mesmo ser submetido ao exame de idade óssea.

No Brasil, portanto, por questões de política criminal, optou-se por um critério rígido. É certo, contudo, sustenta-se uma revisão dessa regra, visto que, em razão da evolução da sociedade, o jovem brasileiro adquire, em idade inferior aos dezoito anos, a capacidade real de compreensão de sua conduta, ao menos para os fatos antijurídicos mais graves, ou seja, aqueles arraigados culturalmente desde tenra idade (homicídio, lesões corporais, estupro etc.).

De todo modo, o Código Penal brasileiro adotou a orientação mais comum entre os diversos países do mundo. ${ }^{35}$ Tanto assim, que o Estatuto do Tribunal Penal Internacional, no que se refere à responsabilidade penal, estabelece que esta principia aos 18 anos. No Estatuto, conforme disposto no artigo 26 do Decreto no 4.388/2002, consta a seguinte regra: “O Tribunal não terá jurisdição sobre menores de 18 anos de idade no momento da prática do crime". Embora seja um dispositivo aparentemente simples e bastante sintético, não foi fácil chegar até a sua redação final. Ressalte-se que, no seio das Nações Unidas, nenhuma previsão de imputabilidade havia surgido até então nos documentos de direito penal internacional. ${ }^{36}$

Havia, entre os diversos Estados que participaram da Conferência de Roma que aprovou o Estatuto de Roma, legislações nacionais com dispositivos os mais diversos sobre o tema, com a idade variando de 7 até 21 anos. ${ }^{37}$ Como se não bastasse a discussão quanto a uma idade determinada, também se pretendeu que a idade fosse relacionada com aquela que dissesse respeito à possibilidade de alistamento nas forças armadas. ${ }^{38}$ Em caso de conflitos armados, muitos dos crimes praticados são de autoria dos militares, pois, nestas conflagrações, cada vez mais se recorre a adolescentes para integrarem as tropas.

Apesar dessa questão, o que se pode constatar é que a menoridade é muito mais uma escolha sócio-política do que médica ou psicológica. Assim, não existe uma idade cientificamente comprovada que determine ter o indivíduo atingido a maturidade necessária para considerá-lo apto a praticar

\footnotetext{
35 JAPIASSÚ, Carlos Eduardo Adriano. O Tribunal Penal Internacional: a internacionalização do direito penal. Rio de Janeiro: Lumen Juris, 2004, p. 181-183.

36 SCHABAS, William A. Princípios gerais de direito penal. In: Tribunal Penal Internacional. São Paulo: RT, 2000, p. 171.

37 SALAND, Per. International Penal law principles. In: The International Penal Court: the making of the Rome Statue - issues, negotiations, results. Haia: Kluwer Law International, 2002, p. 201.

38 SCHABAS, op. cit., p. 172.
} 
crime $^{39}$ e, por essa razão, múltiplas interpretações e propostas e foram apresentadas durante a Conferência de Plenipotenciários.

De outra maneira, a maioria dos países pertencentes à cultura ocidental adotam, como início da imputabilidade penal, a idade de 18 anos, ${ }^{40}$ bem como foi essa a idade proposta no Projeto de Código Penal Internacional, elaborado por Bassiouni. ${ }^{41}$ Dispositivo idêntico pode ser também encontrado, por exemplo, na Carta Europeia dos Direitos da Infância, de 8 de julho de 1992.

Percebe-se que, portanto, como o crime é uma categoria jurídica, o estabelecimento de um patamar em torno da idade mínima necessária para a assunção da responsabilidade penal é mais ligado a uma relação de proporcionalidade e adequação entre a ofensa praticada pelo autor, a medida sancionada pelo Direito e a capacidade de atuação do infrator.

Como ocorre em outros ordenamentos jurídicos, a menção à responsabilidade penal, apesar de simbólica, pode significar apenas e tão-somente medida que, no ordenamento jurídico brasileiro, é considerada extrapenal.

Assim, torna-se fundamental compreender que mais importante que a discussão do patamar de maioridade penal, nesse particular, pode ser a determinação de que tipo de sanção é mais adequada ao ilícito cometido.

Neste contexto, o debate no Brasil, pode ser sintetizado com seus argumentos favoráveis e contrários à redução da maioridade penal.

Entre os argumentos favoráveis à Emenda Constitucional o 171, podem ser destacado que há, no mundo, uma tendência de repenalização do sistema de justiça penal aplicável a menores, isto é, cada vez mais países punem criminalmente adolescentes infratores.

Também, critica-se o chamado modelo de proteção, visto que os menores seriam responsáveis pelo agravamento da delinquência, ao lado de uma excessiva liberalidade do Judiciário com relação aos menores.

Por isso, pedem-se mais sanções penais e menos medidas educativas, por serem mais efetivas.

E, por fim, deveria retornar a adoção de um critério de discernimento.

\footnotetext{
${ }^{39}$ Sobre o tema, vide SÁNCHEZ GARCÍA DE PAZ, Isabel; BLANCO CORDERO, Isidoro. Minorité pénale et Cour Pénale Internationale. Siracusa: ISISC (mimeogr.), 1998. Apresentado durante o Colóquio de Jovens Penalistas sobre o Tribunal Penal Internacional, realizado na sede do ISISC, em Siracusa, de 16 a 22 de setembro de 1998.

${ }^{40}$ SÁNCHEZ GARCÍA DE PAZ e BLANCO CORDERO, op. cit., p. 2

${ }^{41}$ BASSIOUNI, M. Cherif. Derecho penal internacional. Proyecto de Código Penal Internacional. Madrid: Tecnos, 1983, p. 202 e seguintes.
} 
Quanto aos contrários, podem ser referidos, por exemplo, o de que a redução não solucionará o problema da criminalidade, pois o percentual de crimes violentos praticados é ínfimo se comparado com os praticados por adultos.

Também é feita referência às condições carcerárias desumanas no Brasil servirão para transformar jovens em criminosos perigosos, razão pela qual devem ser feitos investimentos sociais e educacionais ao invés da adoção de medidas penais.

Como pode ser notado, todos são argumentos político-criminais, cuja discussão se torno muito complexo, visto que não técnica, mas decorrente da opinião e dos valores de cada indivíduo.

De todos os argumentos que, em geral, são utilizados no debate político criminal, provavelmente, o único argumento efetivamente jurídico é o de que o art. 228, da Constituição Federal, constitui direito individual e, por isso, cláusula pétrea.

René Ariel Dotti ${ }^{42}$ expõe tal entendimento, sustentando que a imputabilidade somente aos 18 anos constituiria uma das garantias fundamentais da pessoa, embora não esteja prevista no Título II da Constituição. Assim sendo, consistiria em direito individual e não poderia ser objeto de emenda constitucional visando a sua abolição, por meio da redução para 16 anos.

Assim, a eventual aprovação de Emenda Constitucional que reduza para 16 anos parece ser medida, no mínimo pouco prática, pois, caos o Supremo Tribunal Federal venha considerar como possível tal modificação na Constituição, isso somente ocorrerá depois de muito tempo, o que fará com que não se produza o resultado pretendido quanto à redução da maioridade penal.

Se, ao contrário, o Supremo Tribunal Federal reconhecer o artigo 228 como cláusula pétrea, o que parece ser o entendimento mais adequado, o esforço empreendido no Congresso Nacional será inútil.

Ao lado dos argumentos político-criminais e do argumento constitucional, parece que um tópico ainda precisa ser lembrado. Talvez o principal argumento utilizado nos debates políticos em torno da necessidade de redução da maioridade penal seja aquele que vislumbra uma suposta maturidade no adolescente maior de dezesseis anos, o que possibilitaria e fundamentaria a sua responsabilização como adulto. Nesse diapasão, torna-se essencial verificar-se o tipo de contribuição que a neurociência tem dado a essa discussão específica para que se possa verificar o potencial de

${ }^{42}$ DOTTI, René Ariel. Curso de direito penal - parte geral. Rio de Janeiro: Forense, 2004, p. 412/413. 
acerto da medida como política pública destinada à contenção da violência urbana praticada por adolescentes.

\section{NEUROCIÊNCIA E RESPONSABILIDADE PENAL}

Um tema muito pouco desenvolvido nas discussões em torno da responsabilidade penal diz respeito a um aspecto que, em regra, só é abordado nos casos de inimputabilidade por insanidade. Quando o artigo 26 do Código Penal traz o critério biopsicológico como determinante para o estabelecimento da inimputabilidade por insanidade, duas podem ser as causas: 1- a doença psiquiátrica levar o indivíduo a não entender o caráter ilícito do fato ou; 2 - a doença psiquiátrica fazer com que, mesmo entendendo o caráter ilícito do fato, o indivíduo não consiga se determinar de acordo com esse entendimento.

Curioso observar que, quando a discussão se desenvolve em torno da inimputabilidade pela insanidade, é comum que apenas um desses aspectos seja trazido à tona. As alegações em torno da conveniência ou não da mudança do patamar da menoridade se situam em discussões que alegam que o adolescente sabe ou não sabe o que faz, traduzindo para a linguagem do Código Penal, é capaz ou não de entender o caráter ilícito do fato.

Apesar disso, não se pode olvidar outra espécie de discussão: seria o adolescente, mesmo entendendo o caráter ilícito do fato, capaz de se determinar de acordo com esse entendimento? Em outros termos, qual a capacidade de contenção do adolescente frente à estímulos, especialmente os relacionados a atividades ilícitas? A título de ilustração, é interessante buscar o caso Roper v. Simmons, julgado em 2005 pela Suprema Corte americana, para se entender essa interseção.

Christopher Simmons tinha 17 anos quando foi preso em 9 de setembro de 1993 pela morte de Shirley Crook ${ }^{43}$. No homicídio, cometido com crueldade, Simmons amarrou o corpo da vítima com fita adesiva, cabos elétricos e jogou-a do alto de uma ponte. A Suprema Corte do estado de Missouri decidiu que a condenação à morte de um menor de dezoito anos estaria proibida pela Oitava Emenda da Constituição Americana em particular na rejeição a punições cruéis ou incomuns. O estado do

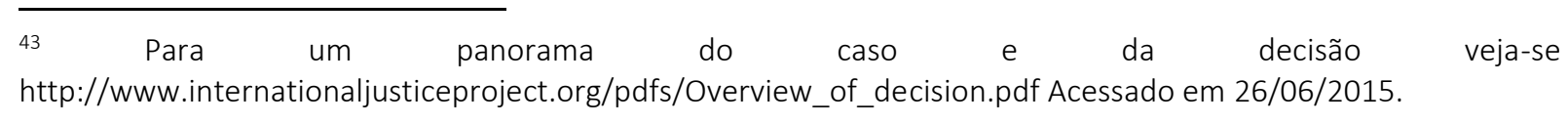


Missouri apelou à Suprema Corte Americana que em 1 de março de 2005 decidiu que a condenação à morte de menores de 18 anos seria inconstitucional nos Estados Unidos. ${ }^{44}$

Nesse particular é interessante entender que dentre os argumentos levados em conta pela Suprema Corte incluem-se o fato de os jovens serem mais vulneráveis a influências negativas e pressões externas, bem como o reconhecimento de que como estão em um estágio transitório da vida e que o seu caráter não é bem formado como o de um adulto.

Especialmente nesse último tópico, argumentos da neurociência foram fundamentais para a decisão da corte. No seu número 305, publicado em julho de 2004, a revista Science ${ }^{45}$ publicou artigo intitulado "Crime, Culpability and Adolescente Brain" onde pontos interessantes são levados em consideração: a parte do cérebro responsável pela contenção de comportamentos impulsivos, o lóbulo (ou lobo) frontal, não inicia seu processo de maturação antes dos dezessete anos, sendo certo que, quando se fala na capacidade de atuar de acordo com o entendimento da ilicitude, é a esse tipo de contenção que se está referindo.

Os cientistas concordam que, durante a adolescência, o cérebro desenvolve um processo de maturação, divergindo sobre o momento final dessa fase, sendo certo que tais distinções variam entre 20 e 25 anos. Segundo Ruben Gur, neurocientista da Universidade da Pensilvânia, adultos comportamse de forma diferente não apenas por possuírem estruturas cerebrais distintas das de um adolescente, mas também porque utilizam essas estruturas de forma diferente:

Fully developed frontal lobe curbs impulses coming from other parts of the brain, Gur explains: "If you've been insulted, your emotional brain says, 'Kill,' but your frontal lobe says you're in the middle of a cocktail party, 'so let's respond with a cutting remark.'.

Beatriz Luna, realizando estudos a partir de ressonâncias magnéticas junto ao cérebro, descobriu que o cérebro muda de uma utilização intensa em determinadas regiões na infância e na adolescência para uma utilização mais interativa, distributiva e colaborativa entre suas regiões na idade adulta.

One of the methods Luna uses to probe brain activity is the "antisaccade" test: a simplified model of real-life responses designed to determine how well the prefrontal cortex governs the

\footnotetext{
${ }^{44}$ A decisão pode ser consultada em http://www.supremecourt.gov/opinions/04pdf/03-633.pdf

45 BECKMAN, Mary. Crime, Culpability and the Adolescent Brain. In Science Magazine. Vol. 305. Jul. 2004. Acessado em 26/06/2015. O artigo pode ser consultado em http://www.sciencemag.org/content/305/5684/596.full.pdf
} 
Como afirma Carlos Orsi ${ }^{46}$ :

more primitive parts of the brain. Subjects focus on a cross on a screen and are told that the cross will disappear and a light will show up. They are told not to look at the light, which is difficult because "the whole brainstem is wired to look at lights," says Luna.

Adolescents can prevent themselves from peeking at the light, but in doing so they rely on brain regions different from those adults use. In 2001, Luna and colleagues showed that adolescents' prefrontal cortices were considerably more active than adults' in this test. Adults also used areas in the cerebellum important for timing and learning and brain regions that prepare for the task at hand.

These results support other evidence showing that teens' impulse control is not on a par with adults'. In work in press in Child Development, Luna found that volunteers aged 14 years and older perform just as well on the task as adults, but they rely mainly on the frontal lobe's prefrontal cortex, whereas adults exhibit a more complex response. "The adolescent is using slightly different brain mechanisms to achieve the goal," says Luna.

O que se sabe, de fato, é que o cérebro jovem é mais vulnerável a estresse, a emoções fortes e tem baixa capacidade de analisar as consequências de longo prazo de suas ações. (...) Resumindo, a melhor evidência científica diz que o cérebro de um jovem de 16 ou 17 anos ainda não atingiu o desenvolvimento pleno de áreas fundamentais para a responsabilidade criminal, como as envolvidas no controle das ações impulsivas, das emoções e da capacidade de resistir à tentação de prazer imediato.

Desta forma, ao que tudo indica, apesar do adolescente eventualmente ser capaz de entender o caráter ilícito de inúmeros fatos, não é inteiramente capaz de determinar-se de acordo com esse entendimento por força da sua menor capacidade de contenção em face de estímulos próprios de comportamentos impulsivos.

\section{CONCLUSÃO}

Percebe-se pelo exposto que o debate sobre a redução da idade penal segue intenso no Brasil e dividindo a sociedade brasileira. Como se trata, no ordenamento jurídico brasileiro, de uma presunção absoluta, depende diretamente de uma opção político-criminal do legislador.

46 ORSI, Carlos. Maioridade penal: uma análise sobre o cérebro dos jovens. In http://revistagalileu.globo.com/blogs/olhar-cetico/noticia/2015/06/maioridade-penal-uma-analise-sobre-ocerebro-dos-jovens.html Acesso em 26/06/2015. 
Não se pode olvidar que tal debate insere-se numa discussão mundial dentro da qual identifica-se uma tendência de revisão e questionamento em torno de uma repenalização do sistema de justiça penal aplicável a adolescentes ${ }^{47}$.

É possível vislumbrar-se críticas ao chamado modelo de proteção, visto que os adolescentes seriam supostamente responsáveis pelo agravamento da delinquência, ao lado de uma excessiva liberalidade do Judiciário com relação aos adolescentes e até mesmo o retorno à adoção de um critério de discernimento para o estabelecimento da maioridade penal.

Certo é também que, ainda que a redução do patamar mínimo para responsabilização criminal seja aprovada no Congresso Nacional, provavelmente vai gerar longa discussão no Supremo Tribunal Federal, visto que não são poucos os autores que defendem o fato da maioridade penal estabelecida no artigo 228 da Constituição Federal representar cláusula pétrea do ordenamento constitucional ${ }^{48}$, o que inviabilizaria a deliberação em torno desse tipo de proposta ${ }^{49}$.

Ademais, viu-se que as mesmas medidas tomadas no Brasil sob a nomenclatura de medidas socioeducativas são mencionadas em ordenamentos jurídicos estrangeiros como medidas de natureza penal. Isso leva à conclusão de que muitas vezes trata-se de uma discussão de caráter simbólico, sendo de vital importância debater-se também a adequação destas medidas às ofensas praticadas.

Salta aos olhos como esse tipo de temática prescinde de um debate mais amplo em face do tipo de política pública adequada ao trato da violência urbana, especialmente àquela praticada por adolescentes. Não se vislumbra a indicação dos resultados atualmente obtidos com as medidas socioeducativas, tampouco uma suposta justificativa dos possíveis motivos que tornariam esse tipo de medida inadequada.

Por isso, insiste-se, parece que tal debate seja mais uma discussão simbólica do que uma tentativa de se formular uma política pública específica com vistas a tentar solucionar os problemas decorrentes da violência urbana praticada por adolescentes. Isso se torna ainda mais claro, quando se

\footnotetext{
47 Basta lembrar o plebiscito de 2014 no qual o Uruguai rejeitou a redução da maioridade penal, lá também estabelecida em dezoito anos. Ver http://www1.folha.uol.com.br/mundo/2014/10/1539324-em-plebiscitouruguai-rejeita-a-reducao-da-maioridade-penal.shtml Acesso em 26/06/2015.

48 Como por exemplo SILVEIRA, Renato de Mello Jorge. A maioridade penal como cláusula pétrea. In http://www.estadao.com.br/noticias/geral,a-maioridade-penal-como-clausula-petrea,1661563 acesso em $26 / 06 / 2015$.

49 O artigo 60, §4으, IV da Constituição Federal estabelece que Não será objeto de deliberação a proposta de emenda tendente a abolir os direitos e garantias individuais
} 
observa que existe legislação específica para crianças e adolescentes em situação de conflito com a lei, cuja reforma, se se considerar necessária, seria mais viável.

Ao contrário, o que se observa é um clamor pela redução da maioridade penal, essencialmente calcada em um argumento, qual seja, na possibilidade de adolescentes serem capazes de entender o caráter ilícito dos fatos por eles cometidos.

Nesse particular, verificou-se que o fundamento da imputabilidade penal, tópico dentro do qual se insere a temática da maioridade penal, não se baseia exclusivamente na capacidade de o indivíduo entender o caráter ilícito do fato, mas também na possibilidade de conseguir determinar seu comportamento de acordo com esse entendimento.

Desta forma, quando se recorreu aos ensinamentos fornecidos pela neurociência, percebeu-se que o adolescente não dispõe de um mesmo aparato cognitivo que o adulto, sendo muitas vezes incapaz de se conter em face de estímulos próprios de comportamentos impulsivos.

Isto ocorre não apenas pelo fato de adolescente não possuir uma maturação cerebral completa, em especial no tocante ao lóbulo frontal, parte do cérebro responsável pela contenção desse tipo de impulso, mas também pelo fato dele não utilizar as áreas do cérebro da mesma maneira que o faz um adulto.

Desta forma, o argumento que equipara a capacidade de compreensão e contenção do adolescente maior de dezesseis anos com a de um adulto parece inaceitável.

Isto posto e independentemente de quaisquer outros argumentos político-criminais, a redução da maioridade penal, conforme estabelece a Proposta de Emenda Constitucional n.o 171, parece politicamente inconveniente, por conta da provável discussão quanto à sua constitucionalidade, visto que existe possibilidade bastante concreta de ser considerada como cláusula pétrea a disposição do artigo 228 da Constituição Federal.

Além disso, a redução para 16 anos parece contrariar a análise científica da questão.

Por esses dois motivos, portanto, considera-se que merece ser reprovada tal proposição.

\section{REFERÊNCIAS BIBLIOGRÁFICAS}

BASSIOUNI, M. Cherif. Derecho penal internacional. Proyecto de Código Penal Internacional. Madrid: Tecnos, 1983.

BECKMAN, Mary. Crime, Culpability and the Adolescent Brain. In Science Magazine. Vol. 305. Jul. 2004. 
BRASIL. Código Criminal do Império do Brasil. Código Penal de 1890 Consolidação das Leis Penais Código Penal de 1940 Código Penal de 1969 Código Penal, com redação da Lei no. 7.209/1984 Constituição Federal de 1988 Lei n. 9 8.069/90

BRUNO, Aníbal. Direito penal, parte geral, tomo 2º: fato punível. Rio de Janeiro: Forense, 2005.

COSTA, Rodrigo de Souza. Direito Penal e Segurança. Rio de Janeiro: GZ Editora, 2012.

DOTTI, René Ariel. Curso de direito penal - parte geral. Rio de Janeiro: Forense, 2004.

MASSA, Patricia Helena. A menoridade penal no direito brasileiro. Revista Brasileira de Ciências Criminais, n. 4, São Paulo: RT, out.-dez. 1993.

JAPIASSÚ. O Tribunal Penal Internacional: a internacionalização do direito penal. Rio de Janeiro: Lumen Juris, 2004.

JESCHECK, Hans-Heinrich; WEIGEND, Thomas. Tratado de Derecho Penal. Parte General. 5a ed. Trad. Olmedo Cardenete. Granada: Comares, 2002.

ORSI, Carlos. Maioridade penal: uma análise sobre o cérebro dos jovens. In: http://revistagalileu.globo.com/blogs/olhar-cetico/noticia/2015/06/maioridade-penal-uma-analisesobre-o-cerebro-dos-jovens.html

OTTENHOF, Reynald. La résponsabilité pénale des mineurs dasn l'ordre interne et internacional. In Revue Internationale de Droit Pénal. 2004/1. Vol. 75. Toulouse, Érès, p. 25-50.

SÁNCHEZ GARCÍA DE PAZ, Isabel; BLANCO CORDERO, Isidoro. Minorité pénale et Cour Pénale Internationale. Siracusa: ISISC (mimeogr.), 1998. Apresentado durante o Colóquio de Jovens Penalistas sobre o Tribunal Penal Internacional, realizado na sede do ISISC, em Siracusa, de 16 a 22 de setembro de 1998

PIERANGELLI, José Henrique. Códigos penais do Brasil: evolução histórica. Bauru: Jalovi, 1980.

Resolutions of the XVII International Congress of Penal Law. In Nouvelles ètudes Pénales. N.21, Toulouse: Érès, 2009, disponível em: http://www.penal.org/sites/default/files/NEP21anglais.pdf

SALAND, Per. International Penal law principles. In: The International Penal Court: the making of the Rome Statue - issues, negotiations, results. Haia: Kluwer Law International, 2002. 
SCHABAS, William A. Princípios gerais de direito penal. In: Tribunal Penal Internacional. São Paulo: RT, 2000.

SHECAIRA. Sérgio Salomão. Sistemas de garantias e o direito penal juvenil. São Paulo: RT, 2008.

SILVEIRA, Renato de Mello Jorge. A maioridade penal como cláusula pétrea. In: http://www.estadao.com.br/noticias/geral,a-maioridade-penal-como-clausula-petrea,1661563

SOUZA, Artur de Brito Gueiros; JAPIASSÚ, Carlos Eduardo Adriano. Curso de direito penal: parte geral. Rio de Janeiro: Elsevier, 2012.

\section{Endereços eletrônicos:}

http://www.internationaljusticeproject.org/pdfs/Overview_of_decision.pdf

http://www1.folha.uol.com.br/mundo/2014/10/1539324-em-plebiscito-uruguai-rejeita-a-reducao-damaioridade-penal.shtml

Trabalho enviado em 28 de junho de 2015.

Aceito em 30 de junho de 2015. 